\title{
An Operational Study of Video Games' Genres
}

\author{
https://doi.org/10.3991/ijim.v14i15.16691
}

\author{
Alaa A. Qaffas \\ University of Jeddah, Jeddah, Saudi Arabia \\ aaqaffasluj.edu.sa
}

\begin{abstract}
This paper presents a study of the most successful games during the last 34 years $(1986-2019)$. We observed that the 100 most ranked games are represented by 16 genres (adventure, role-playing, shooter, platform, puzzle, strategy, hack and slash / beat 'em up, real time strategy, turn-based strategy, point-and-click, indie, racing, sport, fighting, arcade and simulator). These genres are then compared to show which genres are more attractive for players. As a result, we observed that 6 genres among the 16 represent the most ranked games (adventure, RPG, shooter, platform, puzzle, and strategy). They represent 0.83 of the successful games. This allowed us to recommend to combining the others genres with the 6 selected genres. Also, we analyzed the evolution of the 16 games genres during the last 34 years. We observed that some genres have a great success until the past decades, but they haven't a success in this decade. Game designers and researchers in the field of games may rethink about how to add attractive elements in the genres non-successful in this decade. Also, we observed that some genres like the indie games haven't a great success in the past decades, but they have an important increased success in this decade. This may encourage the decision makers and the game designer to invest on these genres.
\end{abstract}

Keywords - Game genres, comparing game genres, evolution of game genres.

\section{$1 \quad$ Introduction}

Video games have an increased and continue interest since the last decades. The importance of video games comes from the big number of gamers who play for some hours each day. These phenomena attract decision makers to invest in the development of video games. Also, several researchers are studying the impact of games in different domains such as education economy and so on. In general, video games carry their importance, from their attractiveness and suspense, because of their spread in houses, games and entertainment places [1].

Furthermore, competitive elements can be incorporated by such games because of their interactivity, which allows for active engagement of the user in the playing process [2]. In particular, video games are a ubiquitous part of almost all children's and adolescents' lives, with 97\% playing for at least one hour per day in the United States [3]. This was a reason for expansion of games. Video gaming is an extremely popular leisure-time activity with more than two billion users worldwide [4] cited in [5]. 
This paper addresses the classification of games based on an operational analysis. We classified and analyzed 100 succeeded games during the last 34 years (1986 - 2019). These games represent 16 game genres (adventure, role-playing, shooter, platform, puzzle, strategy, hack and slash/beat 'em up, real time strategy, turn-based strategy, point-and-click, indie, racing, sport, fighting, arcade and simulator). The 16 game genres are compared based on the number of games representing each one of them. This allowed us to observe the most successful game genres and concluding recommendation for decision makers and researchers in the domain of games. Also, the paper analyses the evolution of the 16 game genres during the last 34 years. This analysis allowed observing the emergent genres and the curve of genres evolution. This could allow predicting the evolution of game genres in the next years.

The rest of the paper is as follows. The section 2 presents the definition of 16 game genres representing the successful games. The section 3 presents the benchmarking of 100 successful games. Section 4 presents the comparative study of game genres based on the classification of games according to their genres. Section 5 presents the evolution of game genres. Finally, the section 6 concludes the papers.

\section{Definitions of Game Genres}

This section presents the game genres of the most successful games during the last decades (1988-2019). These genres represent the first 100 ranked games represented in the next section.

- Adventure games [6] refer to games, which usually have in common a story that drives the gameplay. "Adventure" is usually associated with a quest-like structure.

- A role-playing game [7] is a game set in an imaginary world. Players are free to choose how to explore the game world, in terms of the path through the world they take and may revisit areas previously explored. The amount of the game world potentially available for exploration is typically large.

- First person shooter [8] are characterized by accelerated motor responses yet reduced abilities to cancel a prepotent response.

- Platform games [9] are games in which Characters and settings are seen inside view as opposed to top view, thus creating a graphical sense of "up" and "down" as is implied in "Platform."

- A puzzle game [10] has a solution. In particular, Maze Puzzle is a game where the concept between combination of path and collection of paths, typically from an entrance to a goal.

- A strategy games [11] have the main features of decisions complexity which are taken by the player in a simulated or fantastic politic, economic or military universe.

- A Hack and slash/Beat 'em up game is based on hand-to-hand combat between the player and many non-players characters. 
- Real-time strategy (RTS) games [12] involve multiple teams acting in a real-time environment with the goal of gaining military or territorial superiority over one another. To achieve this goal, a player typically must address two key RTS subproblems, resource production and tactical planning.

- In turn-based strategy (TBS), the player makes his/her move during one turn and then wait for the opponent's turn [13].

- A point-and-click is a game in which the curser (e.g. curser of the mouse) is used as input to click on the game elements.

- An indie game [14] is permeated by spontaneity; ideas freely come and trigger the design without being necessarily forced or induced by the designers and the need to come up with a game to satisfy someone's needs.

- Racing games [15] emulate driving a car on a race track.

- A Sport game simulates a sport in which the player controls the game avatars.

- Fighting games [16] display certain amounts of hand-to-hand combat which can be referred to as a portrayal of violence.

- Arcade video game is a game in which the interface is designed in the form of an arcade (lines) in which the player avatar and others non-player characters move.

- A simulation game allows interacting virtually with phenomena of the real word.

\section{Benchmarking of Successful Games}

Benchmarking is recognised as an essential tool for continuous improvement of quality [17]. Quite often, the benchmarking concept is understood to be an act of imitating or copying. But, in reality this proves to be a concept that helps in innovation rather than imitation, as stated by Thompson and Cox [18] cited in Dattakumar [17]. Also, benchmarking is a tool which helps companies to position themselves Krishnamoorthy and D'Lima [19].in the market place. In fact, decision makers are persistently on the lookout for techniques to facilitate quality enhancement.

This section presents 100 successful games classified according to their genres. This list could serve as benchmarking of successful games for decision makers and researchers who works in improving the quality of games. Furthermore, we have used this list for analyzing the game genres and concluding recommendations. Also, we have analyzed the evolution of the successful game genres during the 34 last years (19862019).

Table 1 presents 100 successful games classified according to their genres. These games are considered as the top best games during 1986 to 2019. They have the best ranks according to the Internet Games Database [20]. The genres of these games are collected during November-December 2019. Most of these games have more than one genre. The game designers combine game genres to attract more players. For example, The Witcher 3: Wild Hunt which is appeared in 2015 has two genres adventure and role-playing (RPG). In adventure games, the player discovers new word and new nonplayer characters in a story. In RPG games, the player could have several paths in the game and could play different role in the game. So, the designer of The Witcher 3: Wild Hunt decided to combine the two game genres adventure and role-playing games. As 
another example of game, we cite the Red Dead Redemption 2 which is appeared in 2018. It has also the shooter genre beside the two genres adventure and RPG. In shooter games, the player has to have rapid decisions and actions.

Table 1. 100 successful games classified according to their genres

\begin{tabular}{|c|c|}
\hline Game & Genres \\
\hline The Witcher 3: Wild Hunt (2015) & Adventure, Role-playing (RPG) \\
\hline War (2018) & Adventure, Role-playing (RPG) \\
\hline Chrono Trigger (1995) & Role-playing (RPG) \\
\hline The Last of Us (2013) & Adventure, Shooter \\
\hline Persona 5 (2016) & Adventure, Platform, Role-playing (RPG) \\
\hline Silent Hill 2 (2001) & Adventure, Puzzle \\
\hline Red Dead Redemption 2 (2018) & Adventure, Role-playing (RPG), Shooter \\
\hline Planescape: Torment (1999) & $\begin{array}{l}\text { Real Time Strategy (RTS), Role-playing (RPG), } \\
\text { Strategy }\end{array}$ \\
\hline Metal Gear Solid 3: Snake Eater (2004) & Adventure, Role-playing (RPG) \\
\hline Paper Mario: The Thousand-Year Door (2004) & Adventure, Role-playing (RPG) \\
\hline Metroid Prime (2002) & Adventure, Platform, Shooter \\
\hline The Legend of Zelda: Breath of the Wild (2017) & Adventure, Role-playing (RPG) \\
\hline Super Mario World (1990) & Platform \\
\hline Baldur's Gate II: Shadows Of Amn (2000) & Role-playing (RPG) \\
\hline Uncharted 4: A Thief's End (2016) & Adventure, Shooter \\
\hline Horizon Zero Dawn (2017) & Role-playing (RPG), Shooter \\
\hline Castlevania: Symphony of the Night (1997) & Adventure, Platform, Role-playing (RPG) \\
\hline Mass Effect 2 (2010) & Role-playing (RPG), Shooter, Simulator \\
\hline The Legend of Zelda: A Link to the Past (1991) & Adventure, Role-playing (RPG) \\
\hline The Legend of Zelda: Ocarina of Time (1998) & Adventure, Platform, Puzzle, Role-playing (RPG) \\
\hline Day of the Tentacle (1993) & Adventure, Point-and-click \\
\hline Super Metroid (1994) & Adventure, Platform, Role-playing (RPG), Shooter \\
\hline Portal 2(2011) & Adventure, Platform, Puzzle, Shooter \\
\hline Metal Gear Solid (1998) & Adventure, Strategy \\
\hline Indiana Jones and the Fate of Atlantis (1992) & Adventure, Point-and-click, Puzzle \\
\hline Bloodborne (2015) & Adventure, Role-playing (RPG) \\
\hline System Shock 2 (1999) & Role-playing (RPG), Shooter \\
\hline Hollow Knight (2017) & $\begin{array}{l}\text { Adventure, Hack and slash/Beat 'em up, Indie, } \\
\text { Platform }\end{array}$ \\
\hline Half-Life 2 (2004) & Shooter \\
\hline Grand Theft Auto V (2013) & Adventure, Racing, Shooter, Sport \\
\hline Final Fantasy VII (1997) & Adventure, Role-playing (RPG) \\
\hline EarthBound (1994) & $\begin{array}{l}\text { Adventure, Role-playing (RPG), Turn-based strategy } \\
\text { (TBS) }\end{array}$ \\
\hline Shadow of the Colossus (2005) & Adventure, Platform, Puzzle \\
\hline Star Wars: Knights of the Old Republic (2003) & Adventure, Role-playing (RPG) \\
\hline Super Mario Odyssey (2017) & Adventure, Platform \\
\hline NieR: Automata (2017) & Role-playing (RPG) \\
\hline Deus Ex (2000) & Role-playing (RPG),Shooter \\
\hline Kingdom Hearts II (2005) & Adventure, Role-playing (RPG) \\
\hline Monkey Island 2: LeChuck's Revenge (1991) & Adventure, Point-and-click, Puzzle \\
\hline
\end{tabular}




\begin{tabular}{|c|c|}
\hline Half-Life (1998) & Adventure, Puzzle, Shooter \\
\hline Super Mario Galaxy 2 (2010) & Adventure, Platform \\
\hline Gothic II (2002) & Adventure, Role-playing (RPG), Strategy \\
\hline Super Mario 64 (1996) & Adventure, Platform \\
\hline Grand Theft Auto: San Andreas (2004) & Adventure, Racing, Shooter, Sport \\
\hline Ori and the Blind Forest (2015) & Adventure, Indie, Platform, Puzzle \\
\hline Red Dead Redemption (2010) & Adventure, Role-playing (RPG), Shooter \\
\hline Uncharted 2: Among Thieves (2009) & Adventure, Platform, Shooter \\
\hline Super Mario World 2: Yoshi's Island (1995) & Platform \\
\hline Super Mario Bros. 3 (1988) & Adventure, Platform \\
\hline Final Fantasy VI (1994) & Adventure, Role-playing (RPG) \\
\hline Celeste (2018) & Adventure, Indie, Platform \\
\hline Fallout 2 (1998) & Role-playing (RPG), Turn-based strategy (TBS) \\
\hline Warcraft III: Reign of Chaos (2002) & Real Time Strategy (RTS), Strategy \\
\hline StarCraft (1998) & Real Time Strategy (RTS), Strategy \\
\hline Gothic (2001) & Adventure, Role-playing (RPG) \\
\hline Tetris (1986) & Arcade, Puzzle, Strategy \\
\hline Super Smash Bros. Melee (2001) & $\begin{array}{l}\text { Fighting, Hack and slash/Beat 'em up, Platform, } \\
\text { Sport }\end{array}$ \\
\hline The Legend of Zelda: Majora's Mask (2000) & Adventure, Role-playing (RPG) \\
\hline Mario Kart 8 (2014) & Adventure, Platform \\
\hline $\begin{array}{l}\text { Heroes of Might and Magic III: The Restoration of } \\
\text { Erathia (1999) }\end{array}$ & $\begin{array}{l}\text { Role-playing (RPG), Strategy, Turn-based strategy } \\
\text { (TBS) }\end{array}$ \\
\hline StarCraft II: Wings of Liberty (2010) & Real Time Strategy (RTS), Strategy \\
\hline Vampire: The Masquerade - Bloodlines (2004) & Adventure, Role-playing (RPG) \\
\hline Dark Souls III (2016) & Adventure, Role-playing (RPG) \\
\hline Resident Evil 4 (2005) & Shooter \\
\hline $\begin{array}{l}\text { Star Wars: Knights of the Old Republic II - The Sith } \\
\text { Lords (2004) }\end{array}$ & Adventure, Role-playing (RPG), Strategy \\
\hline Diablo II (2000) & Hack and slash/Beat 'em up, Role-playing (RPG) \\
\hline The Elder Scrolls V: Skyrim (2011) & Adventure, Role-playing (RPG) \\
\hline Final Fantasy IX (2000) & $\begin{array}{l}\text { Adventure, Role-playing (RPG), Turn-based strategy } \\
\text { (TBS) }\end{array}$ \\
\hline Half-Life 2: Episode Two (2007) & Puzzle, Shooter \\
\hline Stardew Valley (2016) & Adventure, Puzzle, Role-playing (RPG) \\
\hline $\begin{array}{l}\text { The Legend of Zelda: A Link Between Worlds } \\
(2013)\end{array}$ & Adventure, Puzzle, Role-playing (RPG) \\
\hline Marvel's Spider-Man (2018) & Adventure,Hack and slash/Beat 'em up \\
\hline Grand Theft Auto: Vice City (2002) & Adventure, Arcade, Racing, Shooter \\
\hline Mafia (2002) & Adventure, Fighting, Racing, Shooter \\
\hline Super Smash Bros. Ultimate (2018) & Fighting \\
\hline Metal Gear Solid 2: Sons of Liberty (2001) & Adventure \\
\hline The Legend of Zelda: The Wind Waker (2002) & Adventure, Platform, Puzzle, Role-playing (RPG) \\
\hline Undertale (2015) & $\begin{array}{l}\text { Adventure, Indie, Role-playing (RPG), Shooter, } \\
\text { Turn-based strategy (TBS) }\end{array}$ \\
\hline Portal (2007) & Platform, Puzzle, Shooter \\
\hline God of War II (2007) & Adventure, Hack and slash/Beat 'em up, Platform \\
\hline INSIDE (2016) & Adventure, Indie, Platform, Puzzle \\
\hline Super Mario Galaxy (2007) & Adventure, Platform \\
\hline Assassin's Creed II (2009) & Adventure, Platform \\
\hline
\end{tabular}




\begin{tabular}{|l|l|}
\hline Batman: Arkham Asylum (2009) & Adventure, Hack and slash/Beat 'em up \\
\hline BioShock (2007) & Adventure, Role-playing (RPG), Shooter \\
\hline Mass Effect (2007) & Role-playing (RPG), Shooter \\
\hline Max Payne (2001) & Shooter \\
\hline Fallout: New Vegas (2010) & Role-playing (RPG), Shooter \\
\hline Mass Effect 3 (2012) & Adventure, Role-playing (RPG), Shooter \\
\hline The Elder Scrolls III: Morrowind (2002) & Adventure, Role-playing (RPG) \\
\hline Age of Empires II: The Age of Kings (1999) & Real Time Strategy (RTS), Strategy \\
\hline Batman: Arkham City (2011) & Adventure, Hack and slash/Beat 'em up \\
\hline Uncharted 3: Drake's Deception (2011) & Adventure, Platform, Shooter \\
\hline Dead Space 2 (2011) & Shooter \\
\hline The Walking Dead: Season One (2012) & Adventure, Point-and-click \\
\hline DOOM (2016) & Shooter \\
\hline Borderlands 2 (2012) & Role-playing (RPG), Shooter \\
\hline The Elder Scrolls IV: Oblivion (2006) & Adventure, Role-playing (RPG) \\
\hline Dragon Age: Origins (2009) & Role-playing (RPG) \\
\hline Bioshock Infinite (2013) & Adventure, Shooter \\
\hline
\end{tabular}

\subsection{Classification of games according to their genres}

Games are classified according to their genres. Given that a game may belong to more than one genre, it may appear in more than one class. The table 2 presents a classification of most ranked games during 1986-2019. This classification is based on table 1. For example, the number of games is 69 for the game genre adventure. This means that there are 69 games in the table 1 having one of their genre adventure. For more details about the games in each genre, see the appendix 1.

Table 2. Classification of games according to their genres

\begin{tabular}{|l|c|}
\hline \multicolumn{1}{|c|}{ Genres of Games } & Number of Games \\
\hline Adventure & 69 \\
\hline Role-playing (RPG) & 49 \\
\hline Shooter & 32 \\
\hline Platform & 26 \\
\hline Puzzle & 15 \\
\hline Strategy & 10 \\
\hline Hack and slash/Beat 'em up & 7 \\
\hline Real Time Strategy (RTS) & 5 \\
\hline Turn-based strategy (TBS) & 5 \\
\hline Point-and-click & 5 \\
\hline Indie & 5 \\
\hline Racing & 4 \\
\hline Sport & 3 \\
\hline Fighting & 3 \\
\hline Arcade & 2 \\
\hline Simulator & 1 \\
\hline Total & 241 \\
\hline
\end{tabular}


Adventure is the most genre succeeded in the last decades (69 games belong to the genre of adventure games). Then, role-playing (RPG) is represented by 49 games. The shooter, platform, puzzle, and strategy are represented respectively by 32, 26, 15 and 10 games. These genres have good representation in the set of successful games. Hack and slash/beat 'em up, Real Time Strategy (RTS), Turn-based strategy (TBS), pointand-click, Indie, racing, sport, fighting, arcade and Simulator appear also among the successful genres. They represent respectively 7, 5, 5, 5, 5, 4, 3, 3, 2 and 1 games. Given that a game may appear in more than one genre, the total in table 2 is 241 . So, in average a game appear in two or three genres $(2<241 / 100<3)$.

In order to have more observation of the games' repartition into classes, the games' classification is represented in the form of graphic. The figure 1 presents a classification of the most ranked games during 1986-2019.

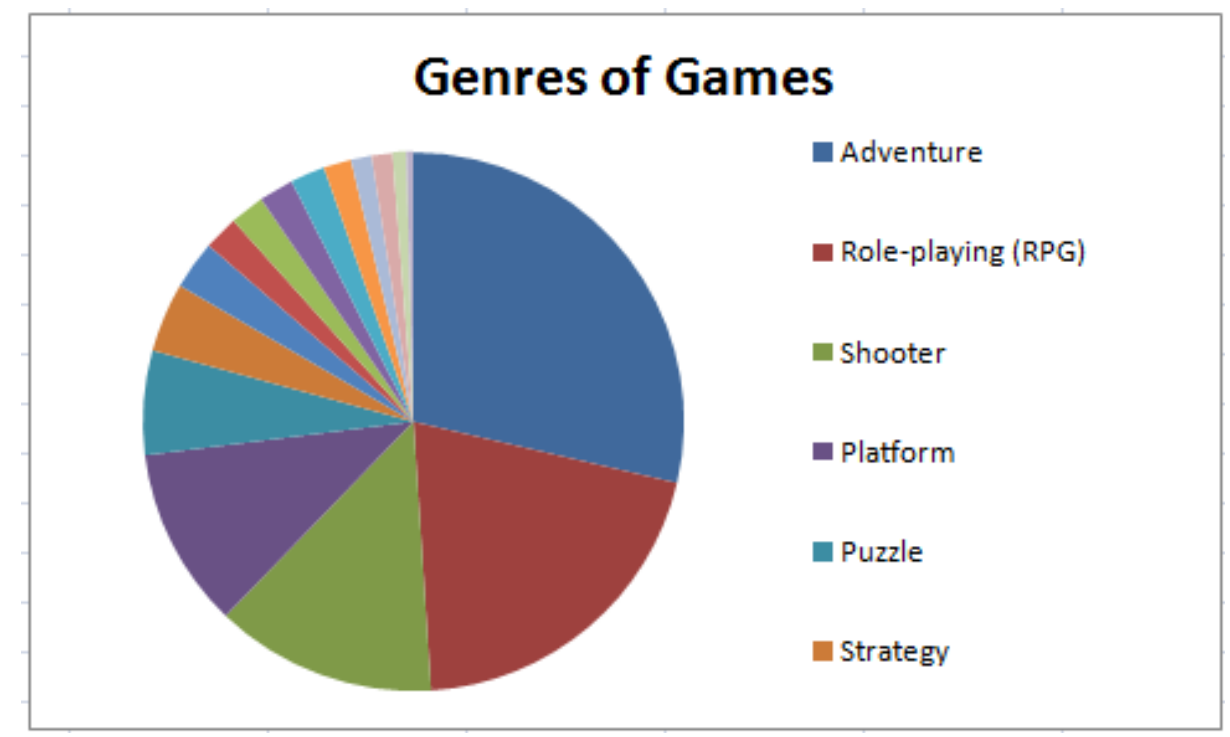

Fig. 1. Classification of games according to their genres

It is possible to observe from figure 1 that 6 genres (adventure, RPG, shooter, platform, puzzle, and strategy) out of 16 represent the most successful games with a rate of $0,83(=201 / 241$, where 241 is the sum of the numbers of games appeared in all genres; 201 is the sum of the numbers of games appeared in the 6 most successful genres.). Some recommendations could be done based on this observation:

- Game designers and entrepreneurs in the games industry could profit from the emergence of the most successful genres by including in their game, the design aspect of these genres: adventure, RPG, shooter, platform, puzzle, and strategy.

- Researchers in educational field may study the usefulness of the most successful genres in the context of education. In fact, several educational games are implemented but they do not appear in the list of most successful games. 
- Researchers in the usability and psychometric analyses may be interested to the analyses of the player behavior towards these game genres.

For more analyses of the successful games during the last decades, we analyze in the next section the evolution of these games. In fact, it is possible that some genres have an increase success in the last years but this success is not seen in global view of 34 years (1986-2019).

\section{Evolution of Games' Genres}

The games of each genre are classified according to 8 periods of time. Each period includes 4 years except the first period which include 6 years. In fact, we have 34 years (= 6 years $+7 * 4$ years) from 1986 to 2019 . The first period is too large given that the number of games in all genres is less in the first period. The defined periods are: 1986 -1991, 1992-1995, 1996-1999, 2000-2003, 2004-2007, 2008-2011, 1012-2015 and 2016-2019. Figure 2 presents 6 histograms representing the evolution of six most successful genres of games (adventure, RPG, shooter, platform, puzzle, and strategy).

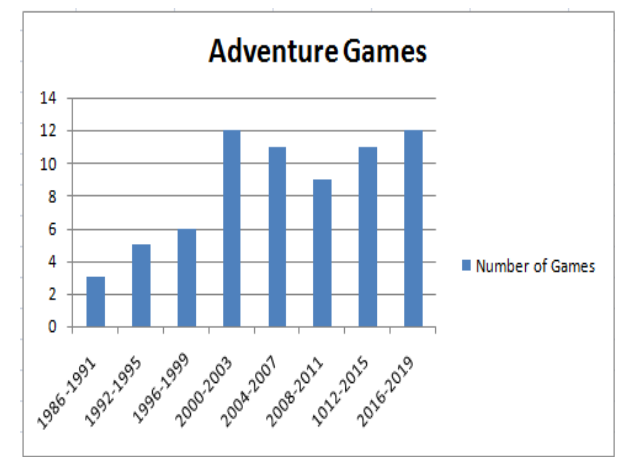

a) Evolution of adventure games

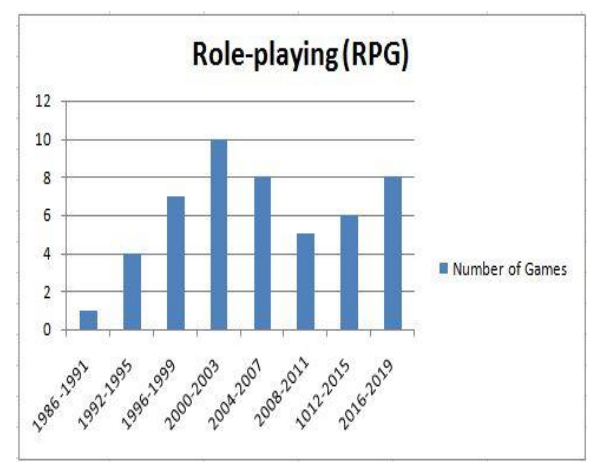

b) Evolution of RPG games
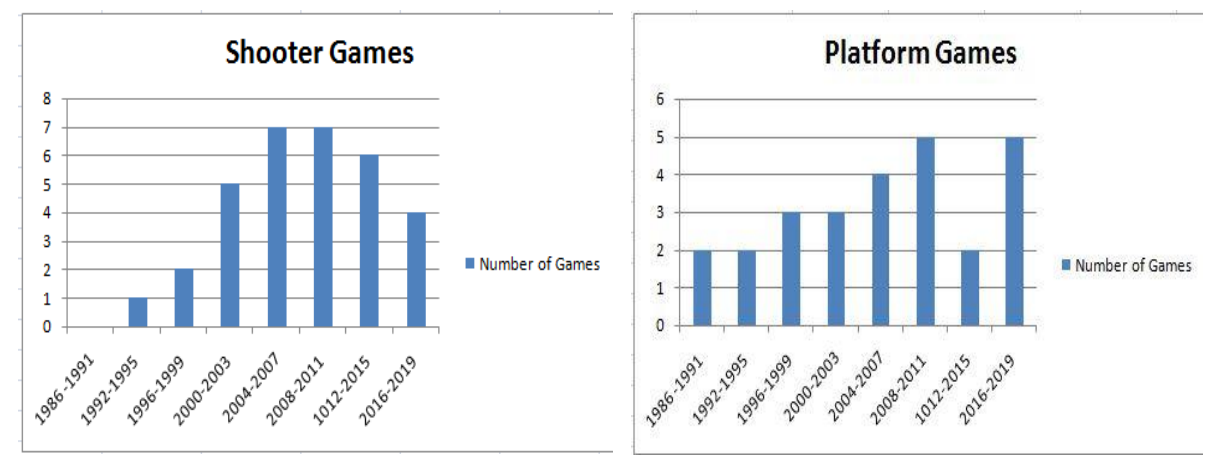
c) Evolution of shooter games

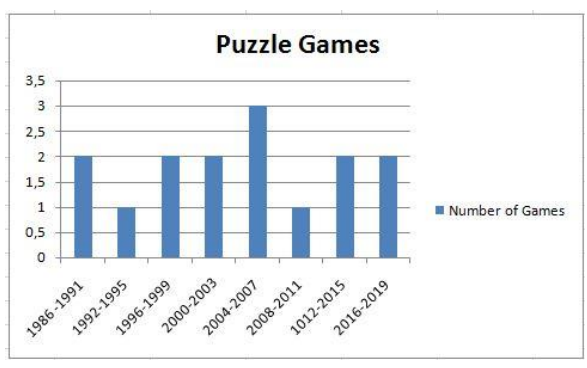

e) Evolution of puzzle games d) Evolution of platform games

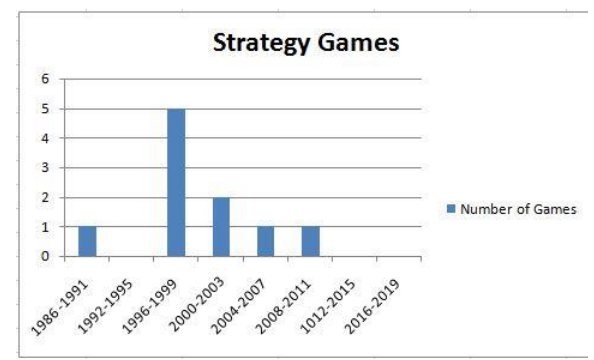

f) Evolution of strategy games

Fig. 2. Evolution of the six most successful genres of games

It is possible to observe that adventure games have achieved their maximal success during two periods: 2000-2003 and 2016-2019. Between these two maximal points, there is a curve which includes a decrease progressively, then an increase progressively. The histogram of the RPG games includes two summit curves (including maximal points: 2000-2003 and 2016-2019) and two curves with minimal points (1986-1991 and 2008-2011). The histogram of successful RPG games may be seen as a spiral including curves with maximal and minimal points. The histogram of the shooter games includes a continue increase until the two successive period 2004-2007 and 2008-2011. Then, the histogram of shooter games starts at continues decrease until 2019. The histogram of the platform games starts with a continue increase until the period 2008-2011. Then, there is a curve with a minimal point in 2012-2015 and a return to increased rates in 2016-2019. The curves exist also in the histograms of the puzzle and strategy games.

The figures 3 and 4 present the evolution of the 10 less successful genres of games. Figure 3 presents the evolution of the genres hack-and-slash, RTS, TBS, point-andclick, indie and racing. Figure 4 presents the evolution of the genres sport, fighting, arcade and simulator.
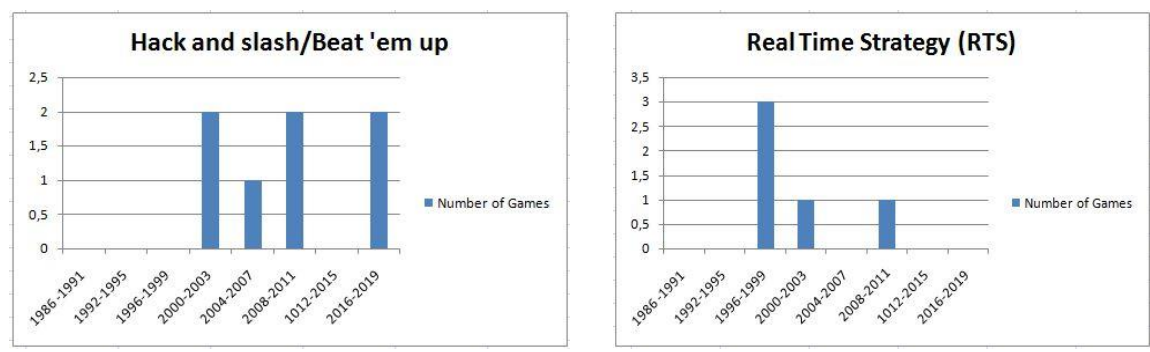
a)Evolution of hack and slash games

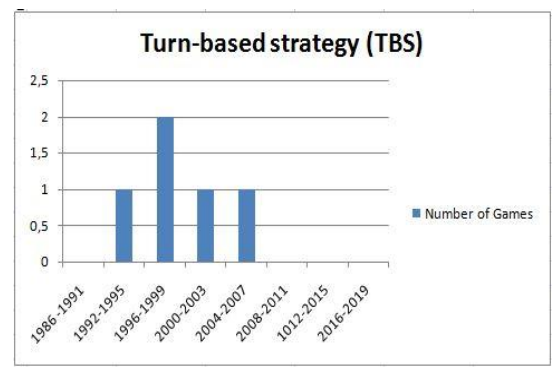

c) Evolution of TBS games

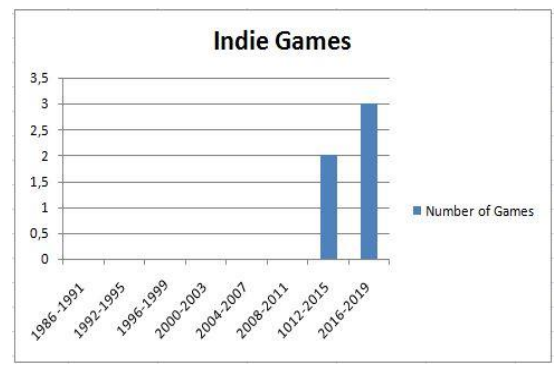

e) Evolution of indie games b). Evolution of RTS games

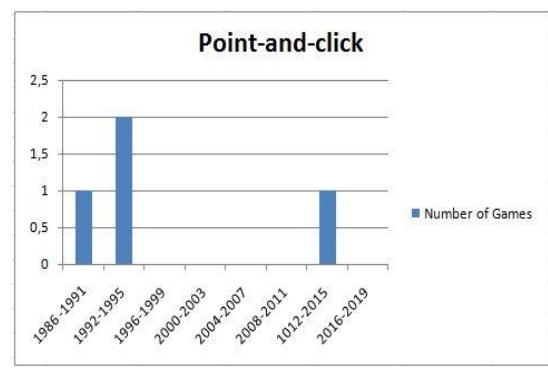

d) Evolution of Point-and-click games

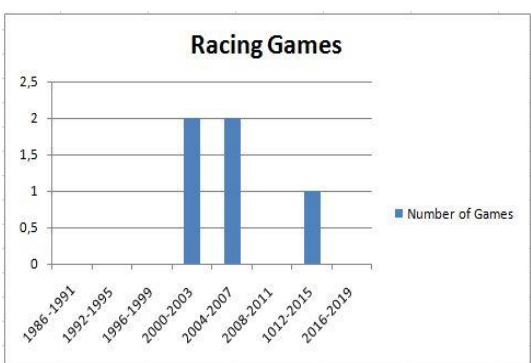

f) Evolution of racing games

Fig. 3. Evolution of the hack and slash, RTS, TBS, point-and-click, indie and racing games.

Hack-and-slash games appeared as successful games in 2000-2013. This genre of games has also appeared as successful genre during the last period 2016-2019. RTS and TBS appeared as successful games until 2011. After that, these two genres do not appear among the successful list. Maybe this is due to the fact that these two genres are based on hard thinking. For example, the chess game is a TBS and needs an important concentration of the players. The point-and-click genre has an important earlier success. Then it does not appear as successful genre during 16 years (1996-2011). The indie games appeared as successful games just in the last period. The histogram of the indie games shows an increase. Racing games achieved their maximal success during tow continuous periods 2000-2003 and 2004-2007. 


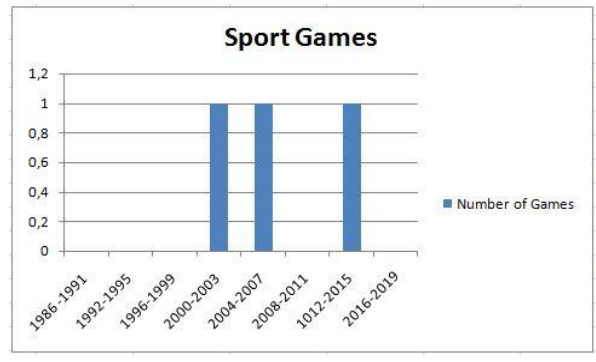

a) Evolution of sport games

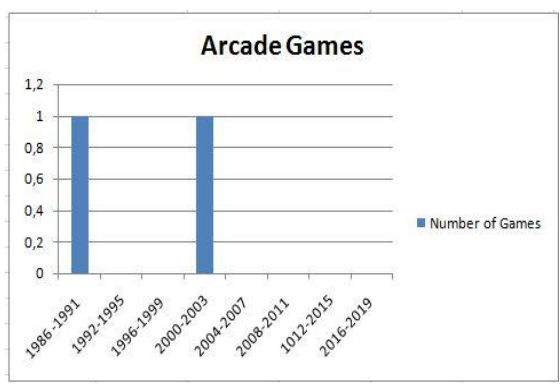

c) Evolution of arcade games

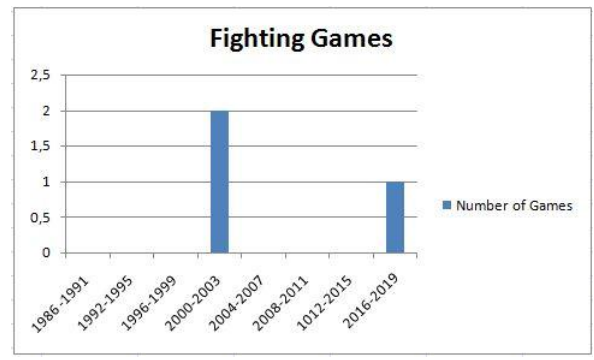

b) Evolution of fighting games

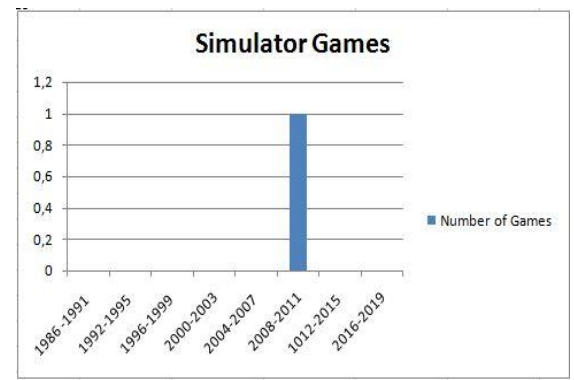

d) Evolution of simulator games

Fig. 4. Evolution of sport, fighting, arcade and simulator games.

Sport, fighting, arcade and simulator genres appeared in the list of successful genres but the number of successful games of these genres is few. It is recommended to combine these genres with the genres of most successful games like the adventure and the RPG games.

\section{Conclusion}

Decision makers and designers need to know what kind of video games are more attractive for players. The analysis of most successful games allows seeing the opportunities of investment in video games. Furthermore, it allows predicting the preference of players in the next years.

This paper analyses 100 successful games during the last 34 years (1986-2019) and classifies them according to their genres in order to show the most successful games' genres. As a result, we observed that there are six games' genres more successful: 
adventure, RPG, shooter, platform, puzzle, and strategy. Some recommendations could be done based on this observation:

Game designers and entrepreneurs in the games industry could profit from the emergence of the most successful genres by including in their game, the design aspect of these genres: adventure, RPG, shooter, platform, puzzle, and strategy.

- Researchers in educational field may study the usefulness of the most successful genres in the context of education. In fact, several educational games are implemented but they do not appear in the list of most successful games.

- Researchers in the usability and psychometric analyses may be interested in the analyses of the player behavior towards the successful games' genres.

For more observation of the success in game genres, we have analyzed their evolution during the last 34 years. As a result, we have the following observations:

- RTS and TBS appeared as successful games until 2011. After that, these two genres do not appear among the successful list. Maybe this is due to the fact that these two genres are based on hard thinking. For example, the chess game is a TBS and needs an important concentration of the players.

- The indie games appeared as successful games just in the last period. This may be considered as opportunities for games' designers and decision makers given that this genre is starting to have its part in the successful list.

Like any research work, this study has some limitations which are as follows:

- The sample size may be extended for having not only 100 successful games, but more successful games. This may generalize the observed results.

- Some aspects of games are not studied like the game-play and the games mechanics. These aspects could be the subject of future studies.

As future works, interested researchers may work on the following perspectives:

- Study of the relations between game genres. In fact, some genres are more attractive for players and there are many potential combinations of the successful genres with the others games' genres.

- Development of new operational taxonomy of successful video games. The new taxonomy may consider the most successful games' genres and giving them high level in the taxonomy.

- Extend the taxonomy by adding more games' genres related to advertising, psychotherapy, enhanced motivations and mixed reality based respectively on $[21,22,23,24]$.

- Enlarge the sample of successful games and generalizing the study.

\section{References}

[1] Mohamed M. Al-Hileh., Nedaa S.I. Ibrahim. (2018). The Advantages and Disadvantages of Electronic Games Played by Children Aged (3-6) Years, from Mothers and Kindergarten 
Teachers' Point of View. International Journal of Applied Engineering Research ISSN 09734562 13(4). (2018). pp. 1805-1812.

[2] Peter Vorderer., Tilo Hartmann., Christoph Klimmt, (2003). Explaining the enjoyment of playing video games: The role of competition. Proceeding of the ICEC ' 03 Proceedings of the second international conference on Entertainment computing. Pp. 1-9. Pittsburgh, Pennsylvania, USA - May 08 - 10, 2003.

[3] Isabela Granic, Adam Lobel, and Rutger C. M. E. Engels. (2003). The Benefits of Playing Video Games. American Psychologist. 69 (1). Pp 66 -78. https://doi.org/10.1037/ $\underline{\mathrm{a} 0034857}$

[4] Newzoo (2017). 2017 Global Games Market Report: Trends, Insights, and Projections Toward 2020. Available at: http://progamedev.net/wp-content/uploads/2017/06/Newzoo Global_Games_Market_Report_2017_Light.pdf (accessed February 16, 2018). https://doi.org/10.18411/a-2017-023

[5] Von der Heiden, J. M., Braun, B., Müller, K. W., \& Egloff, B. (2019). The Association Between Video Gaming and Psychological Functioning. Frontiers in psychology, 10, 1731. https://doi.org/10.3389/fpsyg.2019.01731

[6] Clara Fernández-Vara (2011). "The tribulations of adventure games: integrating story into simulation through performance. BiblioBazaar, 2011. ISBN: 9781243709028.

[7] Hitchens, Michael;Drachen, Anders. (2009). The Many Faces of Role-Playing Games.

[8] International Journal of Role-playing, 2009, p. 3-21. ID: 2397916290.

[9] Jory Deleuze, Maxime Christiaens, Filip Nuyens, Joel Billieux (2017). Shoot at first sight! First person shooter players display reduced reaction time and compromised inhibitory control in comparison to other video game players. Computers in Human Behavior 72. July 2017, Pages 570-576. https://doi.org/10.1016/j.chb.2017.02.027

[10] Angelika Bugl (2014). Thesis. "Player Evaluation of the Level Design of a Platform Game Using Automated Questions Based on Context-Specific Game Metrics. September 2014. University of Applied Sciences, Upper Austria.

[11] Riannatta Adellin, Chen Tet Khuan and Leo David Gertrude (2019). Conceptual Framework Puzzle Game with High Replayability. Journal of Physics: Conf. Series 1228 (2019) 012070 IOP Publishing. https://doi.org/10.1088/1742-6596/1228/1/012070

[12] Viviane Gal, Cécile Le Prado, Stéphane Natkin, Liliana Vega. (2002). "Writing for video games". In Proceedings Laval Virtual (IVRC).

[13] Radha-Krishna Balla and Alan Fern (2009). "UCT for Tactical Assault Planning in RealTime Strategy Games". Proceedings of the 21st International Jont Conference on Artifical Intelligence (IJCAI'09), Pasadena, California, USA, pp. 40-45.

[14] Cecilia Bexander (Januari, 2014). The Strategy Game Art Guide. Thesis in Game Design, Uppsala University.

[15] Pérez Domínguez EA (2019). The design of indie games, a different paradigm. Thesis. BayreuthUniversity. 2019.

[16] Bei Yuan, Eelke Folmer, Frederick C. Harris, Jr. (2011). Game Accessibility: a Survey. Universal Access in the Information Society 10 (1). March 2011. Pp. 81-100. https://doi.org /10.1007/s10209-010-0189-5

[17] Jhon, A. (2019). The influence of playing 3D fighting games in practicing martial arts.

[18] 1st International Conference on Advance and Scientific Innovation (ICASI). Journal of Physics: Conf. Series 1175 (2019). IOP Publishing. https://doi.org/10.1088/17426596/1175/1/011001

[19] Dattakumar, R. (2003). A review of literature on Benchmarking. Benchmarking: An International Journal. 10(3), 2003. pp. 176-209. MCB UP Limited. https://doi.org/10. $\underline{1108 / 14635770310477744}$ 
[20] Thompson, I. and Cox, A. (1997), Don't imitate, innovate, Supply Management, pp. 40-3.

[21] Bala, Krishnamoorthy,. Christine D'Lima. (2014). Benchmarking as a measure of competitiveness. International Journal of Process Management and Benchmarking (IJPMB), 4(3). July 2014. https://doi.org/10.1504/ijpmb.2014.063240

[22] Qaffas, A (2016) Lightweight adaptive personalised e-advertising. PhD thesis, University of Warwick.

[23] Internet Games Database (IGDB, 2019). https://www.igdb.com/top-100/games.

[24] Sie-Yi, L., \& ChePa, N. (2020). Criteria of Mobile Psychotherapy Games for Memory Disorder: A Systematic Literature Review. International Journal of Interactive Mobile Technologies (IJIM), 14(05), pp. 57-72. https://doi.org/10.3991/ijim.v14i05.13345

[25] Nygren, E., Laine, T., \& Sutinen, E. (2018). Dynamics between Disturbances and Motivations in Educational Mobile Games. International Journal of Interactive Mobile Technologies (IJIM), 12(3), pp. 120-141. https://doi.org/10.3991/ijim.v12i3.8490

[26] Fotouhi-Ghazvini, F., Earnshaw, R., Moeini, A., Robison, D., \& Excell, P. (2011). From ELearning to M-Learning - the use of Mixed Reality Games as a new Educational Paradigm. International Journal of Interactive Mobile Technologies (IJIM), 5(2), pp. 17-25. https://doi.org/10.3991/ijim.v5i2.1463

\section{Authors}

Alaa A. Qaffas received the B.S. degree in Computer Science from King AbdulAziz University, Jeddah, Saudi Arabia, in 2007 and the M.S. degree in Computer Science from Hertfordshire University, Hatfield, United Kingdom, in 2010.

Dr. Qaffas completed the Ph.D. degree in Computer Science from the University of Warwick, Coventry, United Kingdom, in 2016. Currently, he is an assistant professor in the Department of Management Information Systems (MIS), College of Business, University of Jeddah, Saudi Arabia. His research interests include e-commerce, adaptive advertising, adaptation model, personalization, user modeling, authoring and delivering personalized content and social networks analysis. He is also conducting research project in the field of educational games and their use for enhancing the motivation of the students. Email: aaqaffas@uj.edu.sa

Article submitted 2020-05-28. Resubmitted 2020-06-29. Final acceptance 2020-06-30. Final version published as submitted by the authors. 


\section{Appendix A}

\begin{tabular}{|c|c|}
\hline Genre of Game & Included Games \\
\hline $\begin{array}{l}\frac{\text { Adventure }}{69 \text { Games }} \\
1986-1991 \text { (3 Games) } \\
1992-1995 \text { (5 Games) } \\
1996-1999 \text { (6 Games) } \\
2000-2003 \text { (12 Games) } \\
2004-2007 \text { (11 Games) } \\
2008-2011 \text { (9 Games) } \\
\text { 1012-2015 (11 Games) } \\
2016-2019 \text { (12 Games) }\end{array}$ & 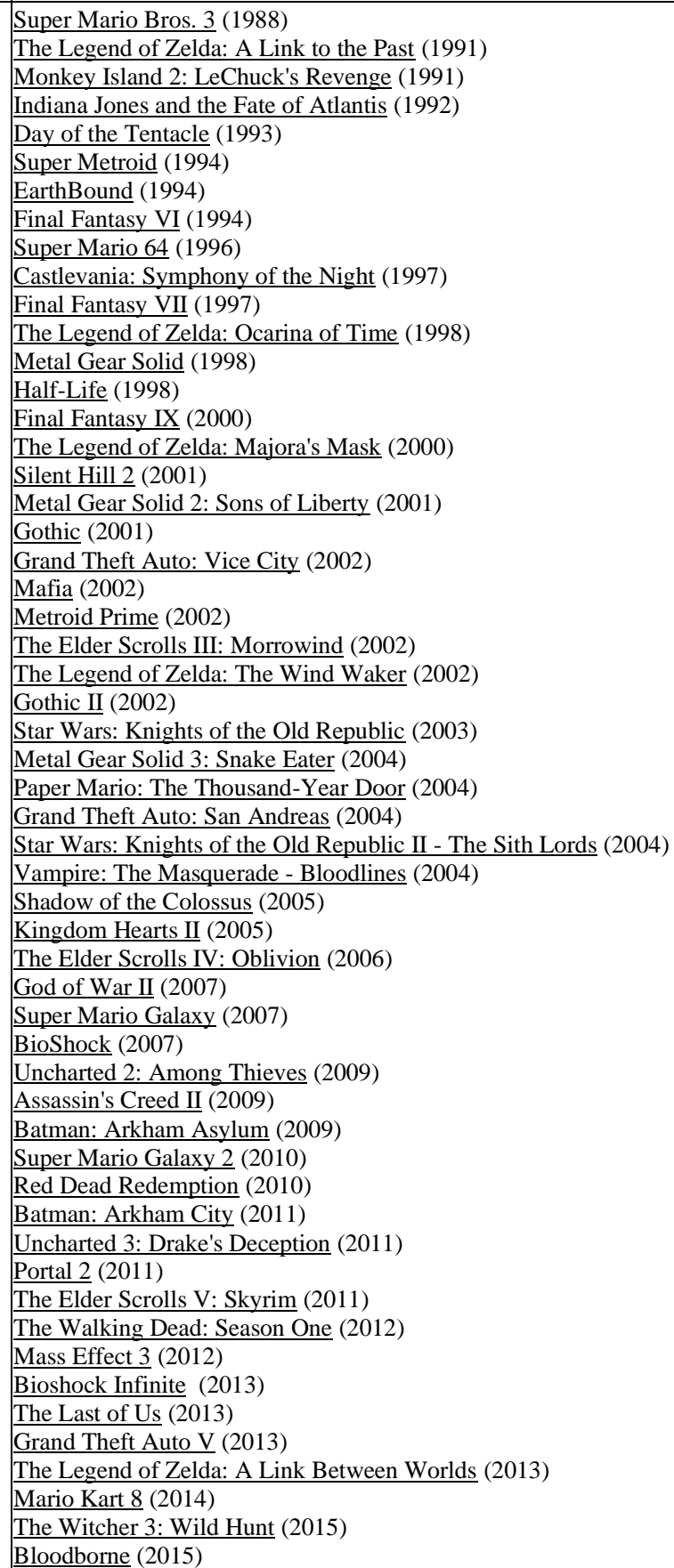 \\
\hline
\end{tabular}




\begin{tabular}{|c|c|}
\hline & $\begin{array}{l}\text { Ori and the Blind Forest (2015) } \\
\text { Undertale (2015) } \\
\text { Persona 5 (2016) } \\
\text { Uncharted 4: A Thief's End (2016) } \\
\text { Dark Souls III (2016) } \\
\text { Stardew Valley (2016) } \\
\text { INSIDE (2016) } \\
\text { The Legend of Zelda: Breath of the Wild (2017) } \\
\text { Hollow Knight (2017) } \\
\text { Super Mario Odyssey (2017) } \\
\text { Celeste (2018) } \\
\text { Marvel's Spider-Man (2018) } \\
\text { War (2018) } \\
\text { Red Dead Redemption 2 (2018) } \\
\end{array}$ \\
\hline $\begin{array}{l}\text { Role-playing (RPG) } \\
49 \text { games } \\
1986 \text {-1991 ( } 1 \text { Games) } \\
1992-1995 \text { ( } 4 \text { Games) } \\
1996-1999 \text { (7 Games) } \\
2000-2003 \text { ( } 10 \text { Games) } \\
2004-2007 \text { (8 Games) } \\
2008-2011 \text { (5 Games) } \\
1012-2015 \text { (6 Games) } \\
2016-2019 \text { (8 Games) }\end{array}$ & 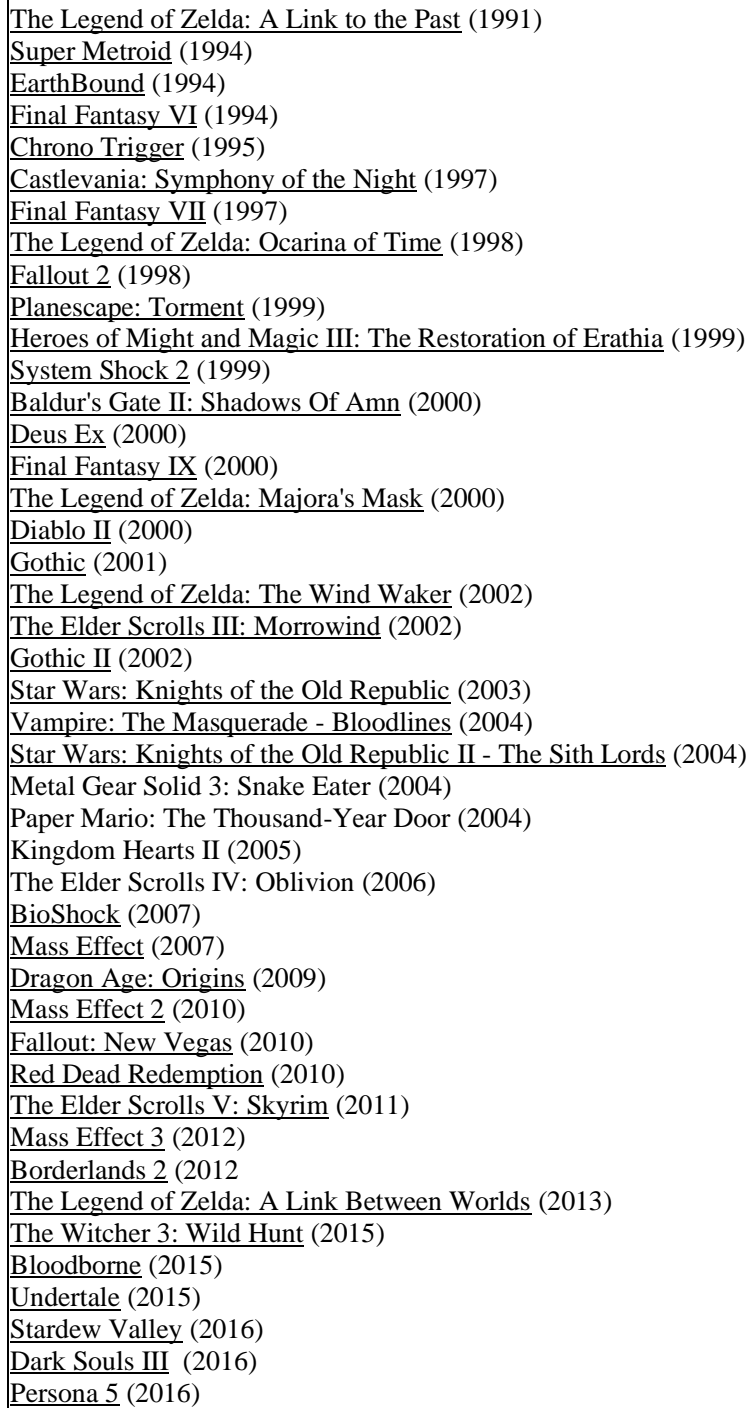 \\
\hline
\end{tabular}




\begin{tabular}{|c|c|}
\hline & $\begin{array}{l}\text { The Legend of Zelda: Breath of the Wild (2017) } \\
\text { Horizon Zero Dawn (2017) } \\
\text { NieR: Automata (2017) } \\
\text { Red Dead Redemption 2 (2018) } \\
\text { War (2018) }\end{array}$ \\
\hline $\begin{array}{l}\frac{\text { Shooter }}{32 \text { games }} \\
1986 \text {-1991 (0 Games) } \\
1992-1995 \text { (1 Games) } \\
1996-1999 \text { (2 Games) } \\
2000-2003 \text { (5 Games) } \\
2004-2007 \text { (7 Games) } \\
2008-2011 \text { (7 Games) } \\
1012-2015 \text { (6 Games) } \\
2016-2019 \text { (4 Games) }\end{array}$ & 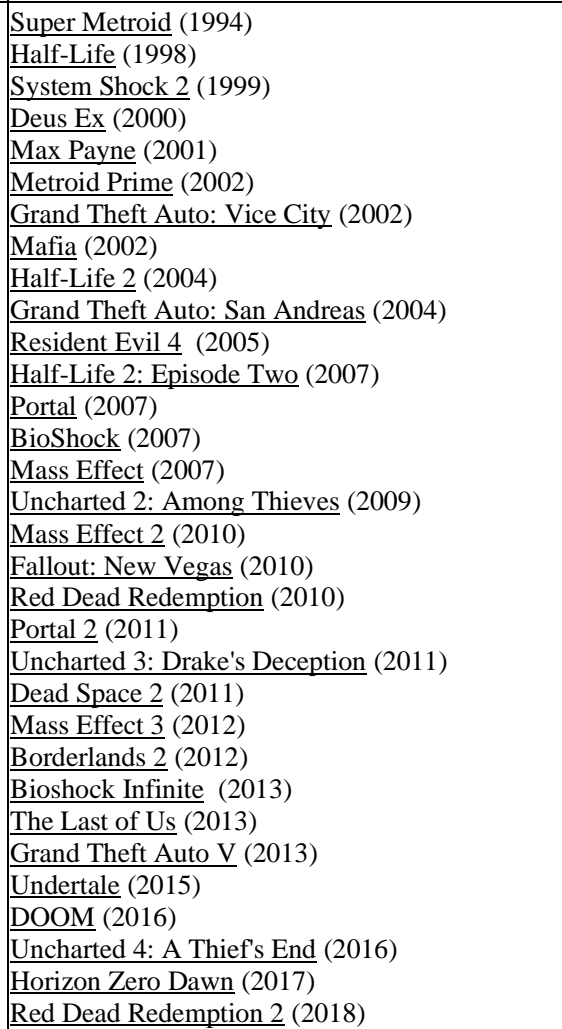 \\
\hline $\begin{array}{l}\frac{\text { Platform }}{26 \text { games }} \\
1986 \text {-1991 (2 Games) } \\
1992-1995 \text { (2 Games) } \\
1996-1999 \text { (3 Games) } \\
2000-2003 \text { (3 Games) } \\
2004-2007 \text { (4 Games) } \\
2008-2011 \text { (5 Games) } \\
1012-2015 \text { (2 Games) } \\
2016-2019 \text { (5 Games) }\end{array}$ & $\begin{array}{l}\text { Super Mario Bros. } 3 \text { (1988) } \\
\text { Super Mario World (1990) } \\
\text { Super Metroid (1994) } \\
\text { Super Mario World 2: Yoshi's Island (1995) } \\
\text { Super Mario 64 (1996) } \\
\text { Castlevania: Symphony of the Night (1997) } \\
\text { The Legend of Zelda: Ocarina of Time (1998) } \\
\text { Super Smash Bros. Melee (2001) } \\
\text { The Legend of Zelda: The Wind Waker (2002) } \\
\text { Metroid Prime (2002) } \\
\text { Shadow of the Colossus (2005) } \\
\text { Portal (2007) } \\
\text { God of War II (2007) } \\
\text { Super Mario Galaxy (2007) } \\
\text { Assassin's Creed II (2009) } \\
\text { Uncharted 2: Among Thieves (2009) } \\
\text { Super Mario Galaxy 2 (2010) } \\
\text { Portal 2 (2011) } \\
\text { Uncharted 3: Drake's Deception (2011) }\end{array}$ \\
\hline
\end{tabular}




\begin{tabular}{|c|c|}
\hline & $\begin{array}{l}\text { Mario Kart 8 (2014) } \\
\text { Ori and the Blind Forest (2015) } \\
\text { INSIDE }(2016) \\
\text { Persona 5 }(2016) \\
\text { Super Mario Odyssey }(2017) \\
\text { Hollow Knight }(2017) \\
\text { Celeste }(2018)\end{array}$ \\
\hline $\begin{array}{l}\frac{\text { Puzzle }}{15 \text { games }} \\
1986-1991 \text { ( } 2 \text { Games) } \\
1992-1995 \text { (1 Games) } \\
1996-1999 \text { (2 Games) } \\
2000-2003 \text { (2 Games) } \\
2004-2007 \text { (3 Games) } \\
2008-2011 \text { (1 Games) } \\
1012-2015 \text { (2 Games) } \\
2016-2019 \text { (2 Games) }\end{array}$ & $\begin{array}{l}\text { Tetris (1986) } \\
\text { Monkey Island 2: LeChuck's Revenge (1991) } \\
\text { Indiana Jones and the Fate of Atlantis (1992) } \\
\text { Half-Life (1998) } \\
\text { The Legend of Zelda: Ocarina of Time (1998) } \\
\text { Silent Hill 2 (2001) } \\
\text { The Legend of Zelda: The Wind Waker (2002) } \\
\text { Shadow of the Colossus (2005) } \\
\text { Half-Life 2: Episode Two }(2007) \\
\text { Portal (2007) } \\
\text { Portal 2 (2011) } \\
\text { The Legend of Zelda: A Link Between Worlds } \\
\text { Ori and the Blind Forest (2015) } \\
\text { Stardew Valley (2016) } \\
\text { INSIDE (2016) }\end{array}$ \\
\hline $\begin{array}{l}\text { Strategy } \\
10 \text { games } \\
1986 \text {-1991 (1 Games) } \\
1992-1995 \text { (0 Games) } \\
1996-1999 \text { (5 Games) } \\
2000-2003 \text { (2 Games) } \\
2004-2007 \text { (1 Games) } \\
2008-2011 \text { (1 Games) } \\
1012-2015 \text { (0 Games) } \\
2016-2019 \text { (0 Games) }\end{array}$ & $\begin{array}{l}\text { Tetris (1986) } \\
\text { Metal Gear Solid (1998) } \\
\text { StarCraft (1998) } \\
\text { Planescape: Torment (1999) } \\
\text { Heroes of Might and Magic III: The Restoration of Erathia (1999) } \\
\text { Age of Empires II: The Age of Kings (1999) } \\
\text { Gothic II (2002) } \\
\text { Warcraft III: Reign of Chaos (2002) } \\
\text { Star Wars: Knights of the Old Republic II - The Sith Lords } \\
\text { StarCraft II: Wings of Liberty (2010) }\end{array}$ \\
\hline $\begin{array}{l}\text { Hack and slash/Beat 'em up } \\
7 \text { Games } \\
1986-1991 \text { (0 Games) } \\
1992-1995 \text { (0 Games) } \\
1996-1999 \text { (0 Games) } \\
2000-2003 \text { (2 Games) } \\
2004-2007 \text { (1 Games) } \\
2008-2011 \text { (2 Games) } \\
1012-2015 \text { (0 Games) } \\
2016-2019 \text { (2 Games) }\end{array}$ & $\begin{array}{l}\text { Diablo II (2000) } \\
\text { Super Smash Bros. Melee (2001) } \\
\text { God of War II (2007) } \\
\text { Batman: Arkham Asylum (2009) } \\
\text { Batman: Arkham City (2011) } \\
\text { Hollow Knight (2017) } \\
\text { Marvel's Spider-Man (2018) }\end{array}$ \\
\hline $\begin{array}{l}\text { Real Time Strategy (RTS) } \\
\text { 5 games } \\
1986 \text {-1991 (0 Games) } \\
1992-1995 \text { (0 Games) } \\
1996-1999 \text { (3 Games) } \\
2000-2003 \text { (1 Games) } \\
2004-2007 \text { (0 Games) } \\
\text { 2008-2011 (1 Games) } \\
1012-2015 \text { (0 Games) } \\
\text { 2016-2019 (0 Games) }\end{array}$ & $\begin{array}{l}\text { StarCraft (1998) } \\
\text { Planescape: Torment (1999) } \\
\text { Age of Empires II: The Age of Kings (1999) } \\
\text { Warcraft III: Reign of Chaos (2002) } \\
\text { StarCraft II: Wings of Liberty (2010) }\end{array}$ \\
\hline$\frac{\text { Turn-based strategy (TBS) }}{5 \text { Games }}$ & \begin{tabular}{|l} 
EarthBound (1994) \\
Fallout 2 (1998)
\end{tabular} \\
\hline
\end{tabular}




\begin{tabular}{|c|c|}
\hline $\begin{array}{l}1986 \text {-1991 (0 Games) } \\
1992-1995 \text { (1 Games) } \\
1996-1999 \text { (2 Games) } \\
2000-2003 \text { (1 Games) } \\
2004-2007 \text { (1 Games) } \\
2008-2011 \text { (0 Games) } \\
1012-2015 \text { (0 Games) } \\
2016-2019 \text { (0 Games) }\end{array}$ & $\begin{array}{l}\text { Heroes of Might and Magic III: The Restoration of Erathia (1999) } \\
\text { Final Fantasy IX (2000) } \\
\text { Undertale (2015) }\end{array}$ \\
\hline $\begin{array}{l}\text { Point-and-click } \\
5 \text { games } \\
1986 \text {-1991 (1 Games) } \\
1992-1995 \text { (2 Games) } \\
1996-1999 \text { (0 Games) } \\
\text { 2000-2003 (0 Games) } \\
\text { 2004-2007 (0 Games) } \\
\text { 2008-2011 (0 Games) } \\
1012-2015 \text { (1 Games) } \\
2016-2019 \text { (0 Games) }\end{array}$ & $\begin{array}{l}\text { Monkey Island 2: LeChuck's Revenge (1991) } \\
\text { Indiana Jones and the Fate of Atlantis (1992) } \\
\text { Day of the Tentacle (1993) } \\
\text { The Walking Dead: Season One (2012) }\end{array}$ \\
\hline $\begin{array}{l}\frac{\text { Indie }}{5 \text { Games }} \\
1986 \text {-1991 (0 Games) } \\
1992-1995 \text { (0 Games) } \\
1996-1999 \text { (0 Games) } \\
2000-2003 \text { (0 Games) } \\
\text { 2004-2007 (0 Games) } \\
2008-2011 \text { (0 Games) } \\
1012-2015 \text { (2 Games) } \\
2016-2019 \text { (3 Games) }\end{array}$ & $\begin{array}{l}\text { Undertale }(2015) \\
\text { Ori and the Blind Forest }(2015) \\
\text { INSIDE }(2016) \\
\text { Hollow Knight }(2017) \\
\text { Celeste }(2018)\end{array}$ \\
\hline $\begin{array}{l}\text { Racing } \\
\text { 4 Games } \\
1986 \text {-1991 (0 Games) } \\
1992-1995 \text { (0 Games) } \\
1996-1999 \text { (0 Games) } \\
2000-2003 \text { (2 Games) } \\
2004-2007 \text { (1 Games) } \\
\text { 2008-2011 (0 Games) } \\
1012-2015 \text { (1 Games) } \\
2016-2019 \text { (0 Games) }\end{array}$ & $\begin{array}{l}\text { Grand Theft Auto: Vice City (2002) } \\
\text { Mafia (2002) } \\
\text { Grand Theft Auto: San Andreas (2004) } \\
\text { Grand Theft Auto V (2013) }\end{array}$ \\
\hline $\begin{array}{l}\text { Sport } \\
3 \text { games } \\
1986 \text {-1991 (0 Games) } \\
1992-1995 \text { (0 Games) } \\
1996-1999 \text { (0 Games) } \\
2000-2003 \text { (1 Games) } \\
2004-2007 \text { (1 Games) } \\
2008-2011 \text { (0 Games) } \\
1012-2015 \text { (1 Games) } \\
2016-2019 \text { (0 Games) }\end{array}$ & $\begin{array}{l}\text { Super Smash Bros. Melee (2001) } \\
\text { Grand Theft Auto: San Andreas (2004) } \\
\text { Grand Theft Auto V (2013) }\end{array}$ \\
\hline $\begin{array}{l}\text { Fighting } \\
\text { 3 Games } \\
\text { 1986 -1991 (0 Games) } \\
\text { 1992-1995 (0 Games) } \\
1996-1999 \text { (0 Games) }\end{array}$ & $\begin{array}{l}\text { Super Smash Bros. Melee (2001) } \\
\text { Mafia (2002) } \\
\text { Super Smash Bros. Ultimate (2018) }\end{array}$ \\
\hline
\end{tabular}




\begin{tabular}{|c|c|}
\hline $\begin{array}{l}\text { 2000-2003 (2 Games) } \\
\text { 2004-2007 (Games) } \\
\text { 2008-2011 (Games) } \\
1012-2015 \text { (Games) } \\
\text { 2016-2019 (1 Games) }\end{array}$ & \\
\hline \begin{tabular}{|l} 
Arcade \\
Games \\
1986 -1991 (1 Games) \\
$1992-1995$ (0 Games) \\
1996-1999 (0 Games) \\
2000-2003 (1 Games) \\
2004-2007 (0 Games) \\
2008-2011 (0 Games) \\
$1012-2015$ (0 Games) \\
$2016-2019$ (0 Games)
\end{tabular} & $\begin{array}{l}\text { Tetris (1986) } \\
\text { Grand Theft Auto: Vice City (2002) }\end{array}$ \\
\hline $\begin{array}{l}\frac{\text { Simulator }}{1 \text { game }} \\
1986 \text {-1991 (0 Games) } \\
1992-1995 \text { (0 Games) } \\
\text { 1996-1999 (0 Games) } \\
\text { 2000-2003 (0 Games) } \\
\text { 2004-2007 (0 Games) } \\
2008-2011 \text { (1 Games) } \\
1012-2015 \text { (0 Games) } \\
2016-2019 \text { (0 Games) }\end{array}$ & Mass Effect 2 (2010) \\
\hline
\end{tabular}

